\title{
Paroxetine combined with fluorouracil plays a therapeutic role in mouse models of colorectal cancer with depression through inhibiting IL-22 expression to regulate the MAPK signaling pathway
}

\author{
HUIJIE ZHANG, MEIXV CHEN, YING LIU, XIAOMEI DONG, CHAN ZHANG, HAN JIANG and XUE CHEN
}

Department of Psychiatry, The First Hospital of China Medical University, Shenyang, Liaoning 110001, P.R. China

Received December 13, 2018; Accepted August 14, 2020

DOI: $10.3892 /$ etm. 2020.9370

\begin{abstract}
The objective of the present study was to observe the therapeutic effect of paroxetine combined with fluorouracil on mice with colorectal cancer (CRC) complicated with depression and to explore its mechanism of action. Using chronic mild stress and xenograft tumor methods to model CRC complicated with depression, $60 \mathrm{BALB} / \mathrm{c}$ mice were randomly divided into control, tumor model, tumor depression model, tumor depression antidepressant, tumor depression chemotherapy and tumor depression antidepressant plus chemotherapeutic drug groups. Changes in mouse sucrose preference and forced swimming tests were tracked. Changes in tumor volume and weight were compared, the tumor inhibition rate was calculated, $\mathrm{Ki}-67$ expression in tumor tissues was detected using immunohistochemistry and IL-22 levels in peripheral blood were detected using ELISAs. Additionally, protein expression levels of IL-22, Bcl-2, Bax, caspase-3, p38, phosphorylated (p)-p38, ERK, p-ERK, JNK and p-JNK in tumor tissue were detected using western blotting. Following treatment with paroxetine and chemotherapy drugs, the sucrose preference index was increased, autonomic behavior dysfunction was alleviated and tumor growth was significantly inhibited. Furthermore, the expression levels of $\mathrm{Ki}-67$ and apoptosis-related proteins, Bax and caspase-3, increased in tumor tissues, anti-apoptosis protein $\mathrm{Bcl} 2$ expression levels decreased significantly, IL-22 levels in the blood and tumor tissues were reduced and p-p38, p-ERK and p-JNK proteins were significantly reduced. It was concluded that paroxetine combined with chemotherapy drugs improved depressive behavior and promoted the survival state in a mouse model of CRC and depression, possibly through
\end{abstract}

Correspondence to: Dr Ying Liu, Department of Psychiatry, The First Hospital of China Medical University, 155 Nanjing North Street, Shenyang, Liaoning 110001, P.R. China

E-mail: liuyingpsy1@163.com

Key words: colorectal cancer, depression, paroxetine, mitogenassociated protein kinase signaling pathway inhibiting IL-22 expression to regulate the activity of the MAPK signaling pathway.

\section{Introduction}

Cancer is a major cause of death worldwide. China is the most populous country in the world and has been estimated to present $\sim 4.51$ million cancer cases and 3.04 million cancer deaths in 2020 (1). Even as research into cancer prevention and treatment increases, cancer is affecting an increasing number of people (2). Since cancer has common characteristics similar to numerous other chronic diseases, including high incidence, long incubation periods and a complex and diverse etiology, it is induced by a variety of risk factors resulting in bodily dysfunction (3). As cancer treatments have improved, cancer progression has been significantly delayed. Currently, cancer has the highest global mortality rate of any chronic disease, exceeding cardiovascular and cerebrovascular diseases and accounting for a total mortality rate of $28.1 \%(4,5)$. CRC, a digestive system tumor, accounts for $1 / 3$ of all malignant tumors $(6,7)$. In China, with changes in the environment and diet, as well as increasing stress and poor living habits, the incidence of CRC is rising and the average age of diagnosis is decreasing (8).

Depressive disorder is a common mental disorder which mainly manifests as a persistent feeling of sadness, slow thinking, psychomotor inhibition, difficulty concentrating and mental and physical fatigue (9). Causes of depression include biological, psychological and social factors, as well as inputs from various life events, which are closely associated to its onset (10). Clinical observations have found that patients with malignant tumors are more likely to be affected by depressive disorder (11). The interaction between tumors and depression often aggravates physical and psychological diseases in patients in a vicious circle (12). Therefore, the role of depressive disorder in tumor development is worth exploring.

It has been demonstrated that immune cells, cytokines and other immune factors serve important roles in tumor occurrence, development and metastasis (13). Immune-related pathogenesis has become a focus of research for tumor etiology $(14,15)$. IL-22 serves key roles in autoimmune diseases and CRC tumor pathogenesis and may be effective 
for analyzing tumor efficacy and prognosis, as well as guiding therapies (16-18). High expression levels of IL-22 in CRC tissue and serum may be associated with the activation or inhibition of related signaling pathways. Phosphorylation of ERK 1/2 by IL-22 has been observed in CRC cells, resulting in the activation of the MAPK signaling pathway, which regulates cell growth, development, differentiation and migration. Following administration with ERK inhibitors, ERK1/2 phosphorylation is inhibited, showing that IL-22 activates MAPK signaling and affects tumor occurrence and development $(19,20)$.

Based on these previous studies, the present study explored the therapeutic effect of antidepressants combined with chemotherapy drugs on CRC and depression in a mouse model of CRC with depressive disorder. The effects on cytokine IL-22 and the MAPK signaling pathway are specifically discussed to provide a reference for the clinical treatment of CRC tumors.

\section{Materials and methods}

Cell culture and preparation. CT-26, a strain of colonic cancer cells from BALB/C mice, was purchased from the Shanghai Cell Bank of the Chinese Academy of Sciences. Cells were seeded in a Petri dish at a density of $1 \times 10^{6} / \mathrm{ml}$ and cultured with DMEM (Gibco; Thermo Fisher Scientific, Inc.) supplemented with 10\% FBS (Gibco; Thermo Fisher Scientific, Inc.) and antibiotics (100 IU/ml penicillin and $100 \mu \mathrm{g} / \mathrm{ml}$ streptomycin) at $37^{\circ} \mathrm{C}$ in a $5 \% \mathrm{CO}_{2}$ incubator. At the logarithmic growth phase, cells were digested with trypsin and centrifuged at $300 \mathrm{x}$ g for $5 \mathrm{~min}$. Cells were collected, washed twice with $0.9 \% \mathrm{NaCl}$ solution and then counted and diluted into a $0.5 \times 10^{5} / \mathrm{ml}$ cell suspension.

Animals and grouping. All animal experiments were approved by the Animal Ethics Committee of the Chinese Medical University (Shenyang, China; approval no. CMU2018178). A total of 60 male BALB/c mice (age, 6 weeks; weight, 25 $\pm 1 \mathrm{~g}$ ) were purchased from Beijing Huafukang Bioscience Co., Inc. [animal production license, SCXK (Jing) 2014-0004]. Mice were housed at $22 \pm 2{ }^{\circ} \mathrm{C}, 40-70 \%$ humidity and 12 -h light/dark cycles with free access to food and water. Mice were randomly divided into 6 groups of 10 mice: i) Cancer model group (CA), mice grafted with CT-26 cells $\left(5 \times 10^{5}\right.$ in $200 \mu \mathrm{l}$ DMEM) through subcutaneous injection to the right armpit; ii) cancer depression model group (CD), in which following CT-26 cell engraftment, depression was established by chronic mild stress from day 1 ; iii) cancer depression with paroxetine group (CDP), CD model mice were intraperitoneally injected with $10 \mathrm{mg} / \mathrm{kg} /$ day paroxetine for 28 days from the 14th day of chronic mild stress; iv) cancer depression with fluorouracil group (CDF), CD mice intraperitoneally injected with $20 \mathrm{mg} / \mathrm{kg} /$ day fluorouracil for 10 days from the 14th day of chronic stress; v) cancer depression with paroxetine and fluorouracil group $(\mathrm{CDP}+\mathrm{F}), \mathrm{CD}$ mice intraperitoneally injected with both $10 \mathrm{mg} / \mathrm{kg} /$ day paroxetine and $20 \mathrm{mg} / \mathrm{kg} /$ day fluorouracil; and vi) control group (CON), mice given equal amounts of saline. Tumor volumes were measured at $0,7,14$, $17,20,23,26,29,32,35,38$ and 42 days and inhibition rate and behavioral changes were calculated. A tumor diameter of $1.5 \mathrm{~cm}$ was set as the humane endpoint. The following formula was used: Tumor inhibition rate $=$ (average tumor weight in
CD mice-average tumor weight in treatment group)/average tumor weight in CD x100\%.

Chronic unpredictable mild stress protocol. Chronic unpredictable mild stress was induced according to previous literature $(21,22)$. Mice in the $\mathrm{CON}$ and CA groups were housed five per cage with normal diet and mice in the other four groups were socially isolated. Stress included $24 \mathrm{~h}$ food deprivation followed by $24 \mathrm{~h}$ water deprivation, $12 \mathrm{~h}$ strobes, $24 \mathrm{~h}$ cage moisture, $24 \mathrm{~h}$ cage tilt at $45^{\circ}, 5$ min cold swimming (at $4^{\circ} \mathrm{C}$ ), or overnight illumination. One stressor was applied each day in a random order and not repeated within 7 days, for 4 continuous weeks.

Sucrose preference experiment. Sucrose preference was tested before and after chronic mild stress. After sucrose adaptation, all mice were deprived of food and water for $12 \mathrm{~h}$. They were then provided with a bottle of $1 \%$ sucrose and a bottle of regular water. Following $12 \mathrm{~h}$ free drinking, the locations of the sucrose bottle and the pure water bottle were exchanged, and mice drank freely for another $12 \mathrm{~h}$. To determine the baseline value of mouse sucrose preference, the following formula was used: Sucrose preference percentage = sucrose consumption/(sucrose consumption + water consumption) $x 100 \%$. The sucrose preference experiment was carried out every 2 weeks from the establishment of each mouse model.

Forced swimming test. The experiment was conducted on two consecutive days. The test was divided into two stages, an adaptation stage at the first day and a test stage at the second day. Mice were placed in a plexiglass cylinder containing $25^{\circ} \mathrm{C}$ clean water. On the first day, the adaptation stage, the mice were released into the water container for $15 \mathrm{~min}$ and then removed, dried and returned to their cages. On the second day, the test stage, the mice were released into the water container and the first two min were not recorded. All movements of the mice were recorded for the next $5 \mathrm{~min}$ and their immobility time was calculated by deducting their mobility time from the total time (5 min). To avoid animal odor interference, the water was replaced after each mouse test $(23,24)$.

Immunohistochemistry. Following completion of the experiment or when tumor size reached the humane endpoint (diameters, $1.5 \mathrm{~cm}$ ), mice were euthanized by cervical dislocation and tumor tissue were fixed in $10 \%$ formalin neutral buffer solution (FUJIFILM Wako Pure Chemical Corporation) at room temperature for $24 \mathrm{~h}$ and embedded in paraffin. Paraffin-embedded sections were cut to $5 \mu \mathrm{m}$ thickness and stained with Ki-67 antibodies (1:300; cat. no. 9449; Cell Signaling Technology, Inc.) for $20 \mathrm{~min}$ at room temperature, followed by staining with horseradish peroxidase (HRP)-labeled anti-rabbit secondary antibodies (1:1,000; cat. no. sc-2357; Santa Cruz Biotechnology, Inc.) for $20 \mathrm{~min}$ at room temperature. Slices were observed using a light microscope to detect $\mathrm{Ki}-67$ expression in tissue. The light density values were analyzed using Image pro-plus software 6.0.(Media Cybernetics, Inc.)

Detection of serum cytokine expression in mice using ELISAs. IL-22 plasma levels in mice were detected by ELISA 

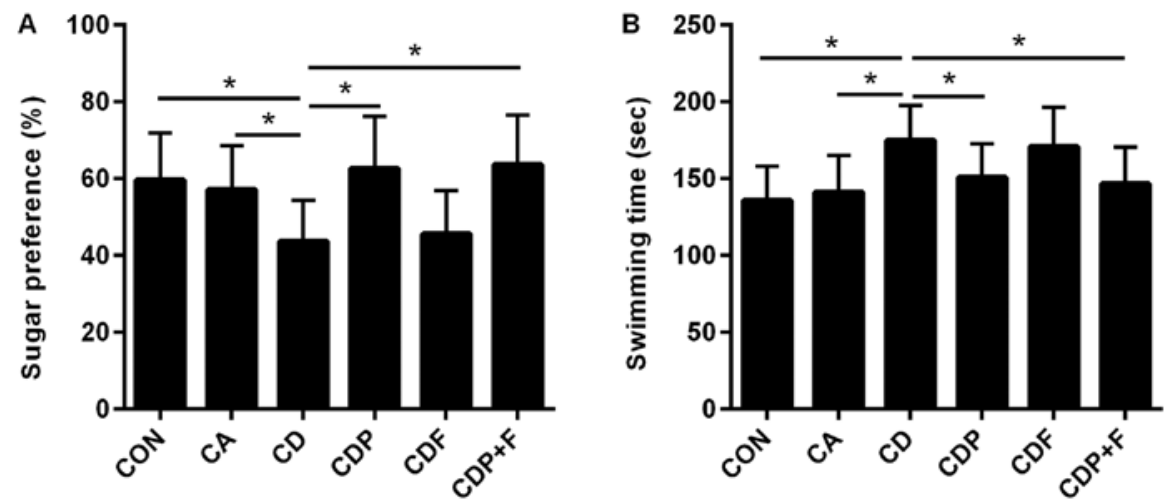

Figure 1. Paroxetine improves behavior in mice with cancer and depression. The sucrose preference test was used to detect the percentage sucrose preference of mice in each group and the forced swimming test was used to detect the swimming time of mice in each group. (A) The percentage sucrose preference of mice. (B) The forced swimming test. ${ }^{*} \mathrm{P}<0.05$. CON, control group; $\mathrm{CA}$, cancer model group; $\mathrm{CD}$, cancer depression model group; $\mathrm{CDP}$, cancer depression with paroxetine group; $\mathrm{CDF}$, cancer depression with fluorouracil group; $\mathrm{CDP}+\mathrm{F}$, cancer depression with paroxetine and fluorouracil group.

(cat. no. ARG80218; Arigo Biolaboratories Corp.), according to the manufacturer's protocol. After incubation at $3^{\circ} \mathrm{C}$ for $1 \mathrm{~h}$, plate 450-nm absorbance values were read using a microplate reader (EXL808; BioTek Instruments, Inc.).

Western blotting. RIPA lysate containing a $10 \%$ protease and phosphatase cocktail (cat. no. ab201119; Abcam) was added to the tumor tissue. Samples were lysed on ice for $30 \mathrm{~min}$, centrifuged at 4,000 x g for $10 \mathrm{~min}$ and the supernatant was collected. Protein concentration was measured using a BCA protein detection kit. After diluting, $30 \mathrm{mg}$ protein/well was separated by $10 \%$ SDS-PAGE electrophoresis, transferred to PVDF membranes and blocked with 5\% skim milk in PBST at room temperature for $1 \mathrm{~h}$. Membranes were independently incubated with antibodies for IL-22 (1:1,000; cat. no. ab133545), Bcl-2 (1:1,000; cat. no. ab32124), Bax (1:1,000; cat. no. ab32503), caspase-3 (1:1,000; cat. no. ab13847), p38 (1:1,000; cat. no. ab170099), phosphorylated (p)-p38 (1:1,000; cat. no. ab47363), ERK (1:1,000; cat. no. ab184699), p-ERK (1:1,000; cat. no. ab201015), JNK (1:1,000; cat. no. ab179461) or p-JNK (1:1,000; cat. no. ab124956) and GAPDH $(1: 1,000$; cat. no. ab8245), then incubated at $4^{\circ} \mathrm{C}$ overnight. After rinsing with TBS-0.05\% Tween-20, Goat anti-rabbit HRP antibodies were added (1:1,000; cat. no. ab6721) and incubated for $2 \mathrm{~h}$ at room temperature. All antibodies were purchased from Abcam. Membranes were developed using the ECL luminescence kit (cat. no. 32106; Thermo Fisher Scientific, Inc.) and imaged using a gel imaging system. Gray values were analyzed by ImageJ software (version no. 1.49; National Institutes of Health).

Statistical analysis. SPSS 22.0 (IBM Corp.) was used for statistical analysis of measurements and quantification. All data were analyzed by one-way ANOVA with Tukey's multiple comparison post hoc test. $\mathrm{P}<0.05$ was considered to indicate a statistically significant difference. The data are presented as the mean \pm standard error. Each experiment was repeated $\geq 3$ times.

\section{Results}

Paroxetine may improve behavior in mice with cancer and depression. Sucrose preference tests showed a lower sucrose preference percentage in the CD mice than in the CON or CA groups $(\mathrm{P}<0.05)$. While chronic unpredictable mild stress reduced sucrose preference values in the $\mathrm{CD}$ group, there was no difference between the $\mathrm{CA}$ and $\mathrm{CON}$ groups $(\mathrm{P}>0.05)$. The percentage of sucrose preference of mice in the $\mathrm{CD}$ group was smaller than the CDP $(\mathrm{P}<0.05)$ and $\mathrm{CDP}+\mathrm{F}$ groups $(\mathrm{P}<0.05)$. There was no significant difference in sucrose preference between the $\mathrm{CDF}$ and $\mathrm{CD}$ groups $(\mathrm{P}>0.05)$. These results suggested that paroxetine antidepressant therapy may reverse changes in sucrose preference caused by chronic stress and that fluorouracil has no effect on sucrose preference in mice (Fig. 1A).

The forced swimming test showed similar results. The swimming time in the CD group was longer than in the CON and $\mathrm{CA}$ groups $(\mathrm{P}<0.05)$, with no difference between the $\mathrm{CA}$ and $\mathrm{CON}$ groups $(\mathrm{P}>0.05)$. After paroxetine treatment, the swimming time of mice in the CDP group was shortened $(\mathrm{P}<0.05)$, while fluorouracil had no effect on swimming time in mice $(\mathrm{P}>0.05)$ compared with the $\mathrm{CD}$ group. These results showed that paroxetine may improve the depressive behavior of mice with cancer and depression (Fig. 1B).

Paroxetine combined with chemotherapy inhibits tumor growth in mice. According to the dynamic tumor growth curve, tumor-bearing mice in each group showed an overall growth trend. Tumor volumes grew largest and fastest in the CD mice, followed by the CDP group. In the CDF and $\mathrm{CDP}+\mathrm{F}$ groups after 26 days of inoculation (10-day drug intervention), tumors maintained slow or even decreased growth until the 32nd day, when tumor growth rate accelerated and tumor volumes increased in all tumor groups. Tumors in CD mice grew faster than in CA mice (Fig. $2 \mathrm{~A}$ and $\mathrm{D} ; \mathrm{P}<0.05$ ), suggesting that the depressive disorder promoted tumor growth. As compared to CD group, tumor growth was slower in the CDF and CDP groups, and tumor growth was the slowest in the CDP+F group (Fig. $2 \mathrm{~A}$ and $\mathrm{D} ; \mathrm{P}<0.05$ ). On the 42nd day, $\mathrm{CD}$ group mice had the largest tumor volume and $\mathrm{CDP}+\mathrm{F}$ mice had the smallest tumor volume (Fig. 2A and D; $\mathrm{P}<0.05)$. As showed in Fig. 2B the difference of tumor weight in different groups were similar to the difference of the tumor volumes among different groups at day 42 in Fig. 2A. The CD Group had the largest tumor weight and the 

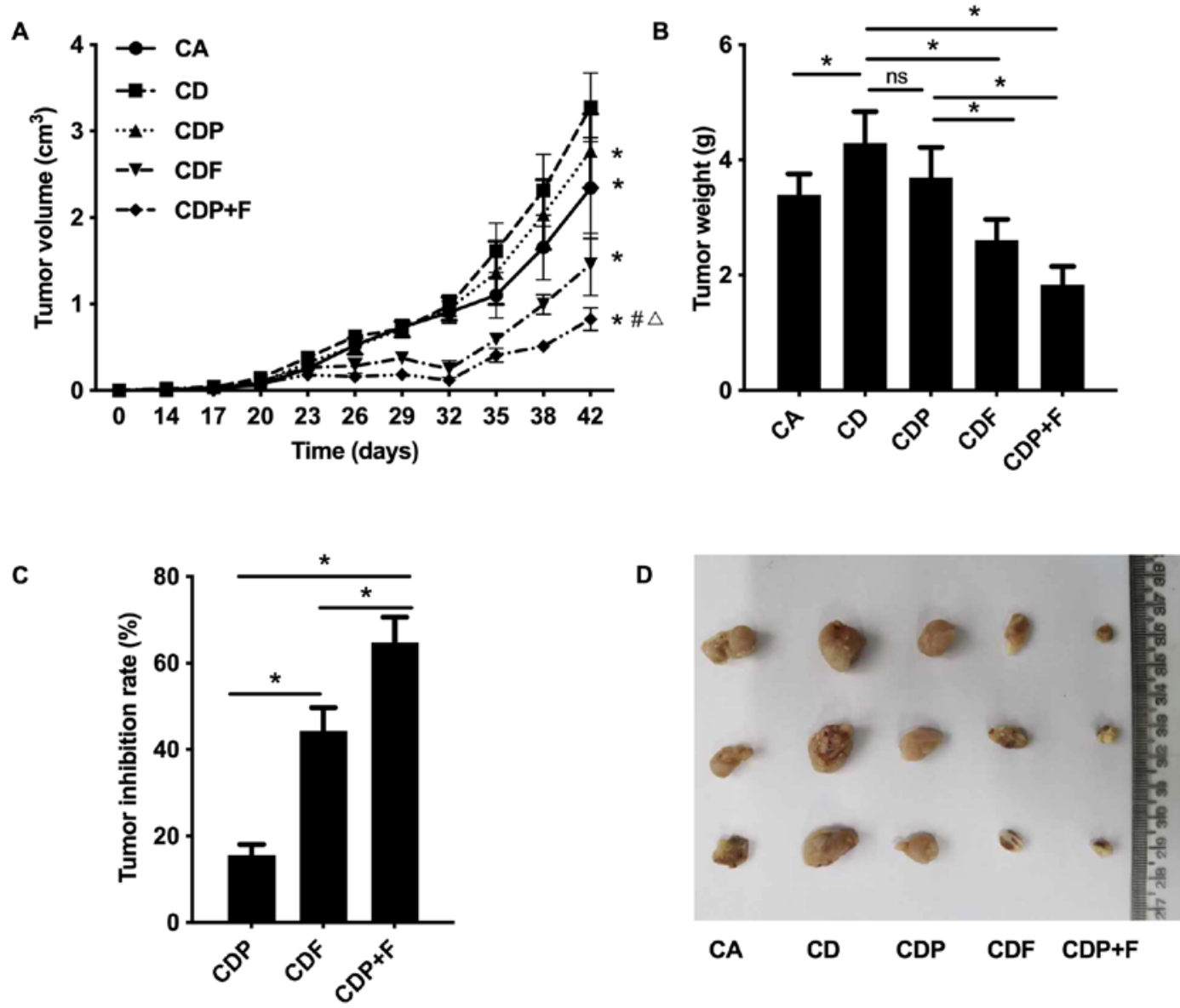

Figure 2. Paroxetine combined with fluorouracil inhibits xenograft tumor growth in mice. Tumor-bearing mice were used to detect tumor growth in each group. (A) The dynamic growth curve of tumor volume. ${ }^{*} \mathrm{P}<0.05$ compared to the $\mathrm{CD}$ group. ${ }^{*} \mathrm{P}<0.05$ compared to the $\mathrm{CDP}$ group. ${ }^{\Delta} \mathrm{P}<0.05$ compared to the CDF group. (B) The tumor weight of the various groups on the 42 nd day. (C) The inhibition rate of tumors. " $\mathrm{P}<0.05$. (D) Photos of tumor xenografts. CA, cancer model group; $\mathrm{CD}$, cancer depression model group; $\mathrm{CDP}$, cancer depression with paroxetine group; $\mathrm{CDF}$, cancer depression with fluorouracil group; $\mathrm{CDP}+\mathrm{F}$, cancer depression with paroxetine and fluorouracil group.

$\mathrm{CDP}+\mathrm{F}$ group had the smallest. Fluorouracil inhibited tumor growth and reduced tumor weight. Furthermore, fluorouracil combined with paroxetine was more effective; however, paroxetine alone only demonstrated a trend to inhibit tumor growth which was not found to be significant $(\mathrm{P}>0.05$; Fig. 2A and B).

Comparing the tumor inhibition rate of mice in each drug treatment group, the $\mathrm{CDP}+\mathrm{F}$ group had the highest inhibitory rate $(\mathrm{P}<0.05)$ followed by the $\mathrm{CDF}$ group, with the $\mathrm{CDP}$ group having the lowest inhibitory rate. This demonstrated that combined treatment with paroxetine and fluorouracil had a better inhibitory effect on tumor growth in mice with CRC and depression (Fig. 2C).

Tumor cell proliferation is inhibited by paroxetine combined with fluorouracil. To detect the proliferation of tumor cells in various groups, $\mathrm{Ki}-67$ staining was used. $\mathrm{Ki}-67$ expression in the $\mathrm{CDF}$ and $\mathrm{CDP}+\mathrm{F}$ groups was significantly lower than in the $\mathrm{CD}$ group $(\mathrm{P}<0.05)$, with the lowest Ki-67 rate in the $\mathrm{CDP}+\mathrm{F}$ group. Although paroxetine alone in the $\mathrm{CDP}$ group was not indicated to inhibit Ki67 expression significantly compared with the $\mathrm{CD}$ group $(\mathrm{P}>0.05)$, the combination of paroxetine and fluorouracil inhibited tumor cell proliferation in mice with CRC and depression (Fig. 3).
Paroxetine combined with fluorouracil promotes tumor cell apoptosis in mice. The expression levels apoptosis-related proteins Bcl-2, Bax and cleaved-caspase-3 were detected by western blotting. Bax and cleaved-caspase-3 expression levels significantly increased and Bcl-2 expression significantly decreased $(\mathrm{P}<0.05)$ in the $\mathrm{CDF}$ and $\mathrm{CDP}+\mathrm{F}$ groups compared with the $\mathrm{CD}$ group. Paroxetine treatment alone had no effect on Bax, Bcl-2 or cleaved-caspase- 3 expression compared with the $\mathrm{CD}$ group $(\mathrm{P}>0.05)$. Expression levels of Bax and cleaved-caspase-3 levels were significantly increased, and $\mathrm{Bcl}-2$ levels significantly decreased in the $\mathrm{CDP}+\mathrm{F}$ group compared with the CDF group $(\mathrm{P}<0.05)$. Thus, combining paroxetine and fluorouracil in $\mathrm{CDP}+\mathrm{F}$ group promoted tumor cell apoptosis in mice with CRC and depression compared to $\mathrm{CDF}$ ( $\mathrm{P}>0.05)$, indicating that paroxetine and fluorouracil exhibited synergistic effects (Fig. 4).

Paroxetine combined with fluorouracil may reduce IL-22 levels. ELISAs and western blotting were used to detect IL-22 expression levels in mouse blood and tumor tissues. The protein levels of IL-22 in the serum and tissues of CD mice was significantly increased compared to $\mathrm{CA}$ mice $(\mathrm{P}<0.05)$; however, IL-22 was reduced by both paroxetine or fluorouracil, with paroxetine combined with fluorouracil reducing IL-22 
A
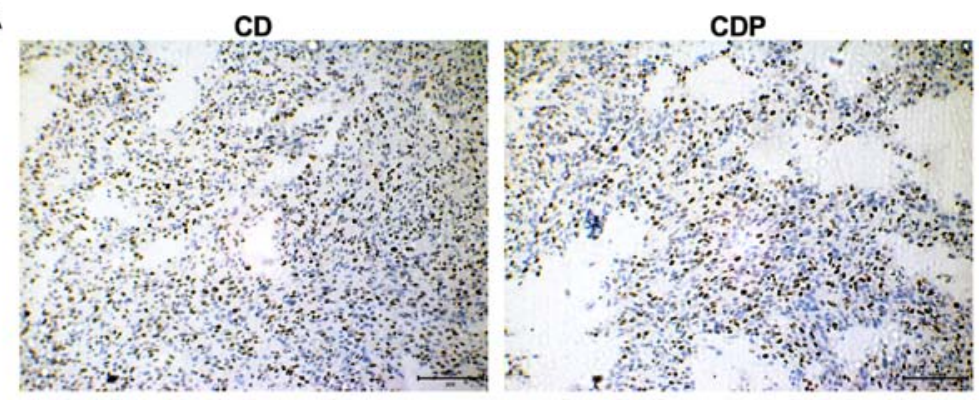

CDF

$\mathrm{CDP}+\mathrm{F}$

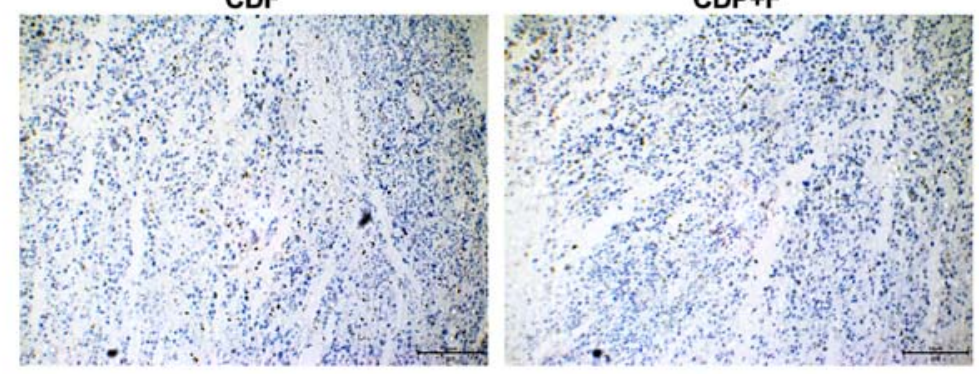

B

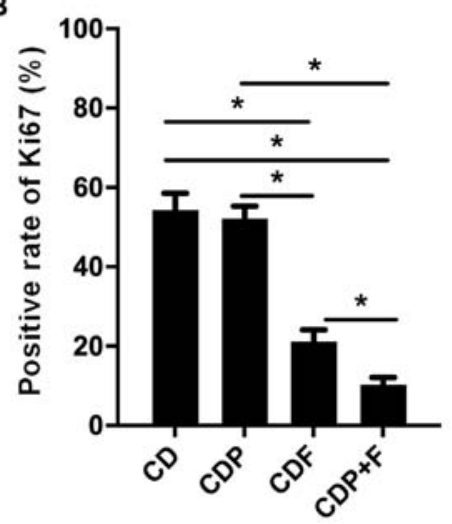

Figure 3. Inhibition of tumors in mice by paroxetine combined with fluorouracil. Ki-67 was examined by immunohistochemistry in each group. (A) Representative images and (B) quantification of immunohistochemistry (scale bar, $50 \mu \mathrm{m}$ ). ${ }^{*} \mathrm{P}<0.05$. CA, cancer model group; CD, cancer depression model group; CDP, cancer depression with paroxetine group; $\mathrm{CDF}$, cancer depression with fluorouracil group; $\mathrm{CDP}+\mathrm{F}$, cancer depression with paroxetine and fluorouracil group.

A

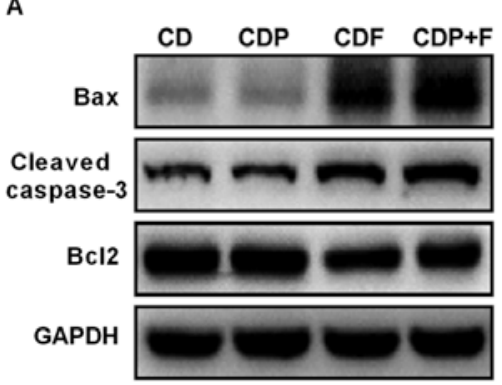

B

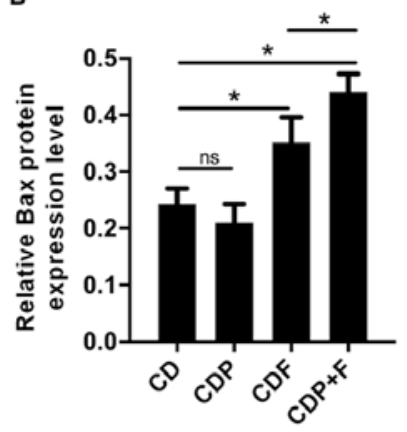

c

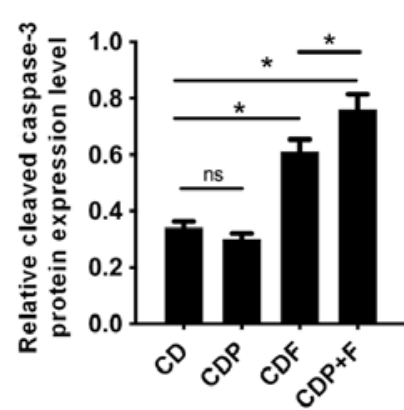

D

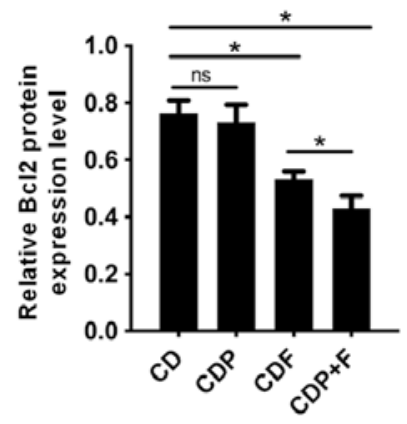

Figure 4. Paroxetine combined with fluorouracil promotes apoptosis of tumor cells in mice. The apoptosis-related proteins as detected using western blotting. (A) Representative blots. Quantification of (B) Bax, (C) cleaved-caspase-3 and (D) Bcl-2. "P<0.05. CD, cancer depression model group; CDP, cancer depression with paroxetine group; $\mathrm{CDF}$, cancer depression with fluorouracil group; $\mathrm{CDP}+\mathrm{F}$, cancer depression with paroxetine and fluorouracil group.

level the most when compared to all cancer and depression groups $(\mathrm{P}<0.05$; Fig. 5A-C).

Paroxetine combined with fluorouracil inhibits activation of the MAPK signaling pathway. To evaluate whether paroxetine combined with fluorouracil inhibits the growth of CRC cells by inhibiting IL-22 expression, thus blocking the MAPK signaling pathway, western blotting was used to detect the expression of MAPK signaling pathway-related proteins p38, p-p38, ERK, p-ERK, JNK and p-JNK. 
A

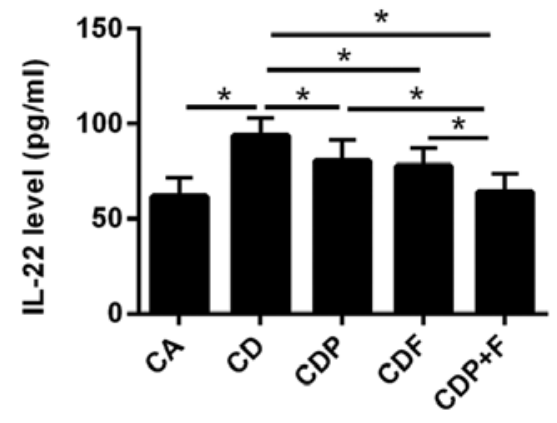

B

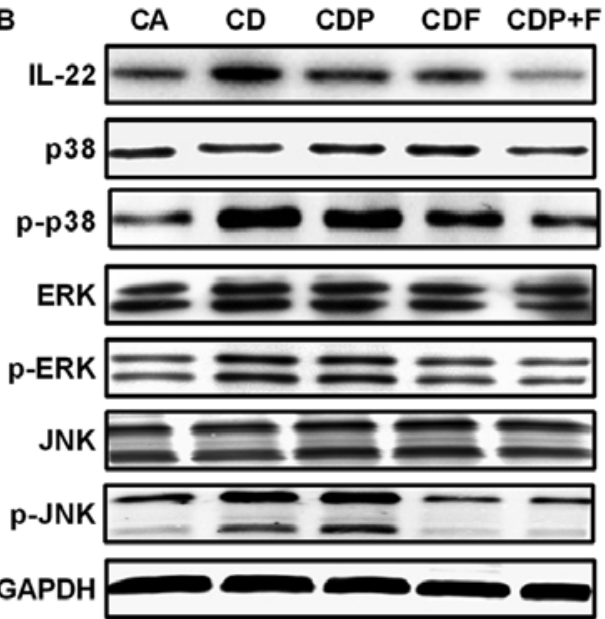

C

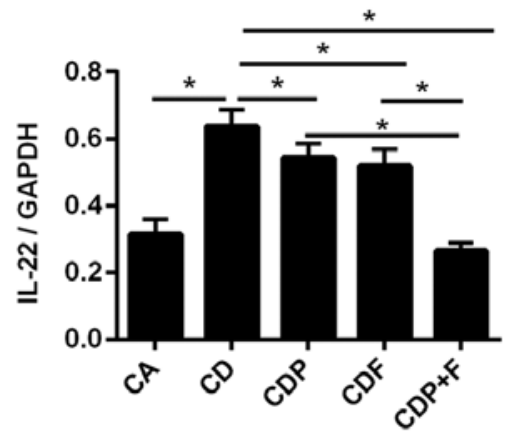

D

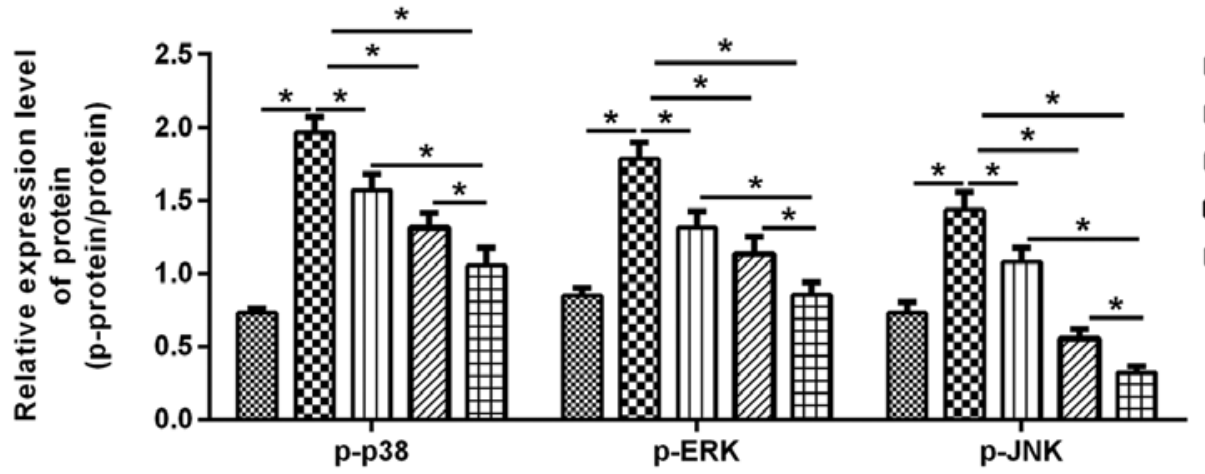

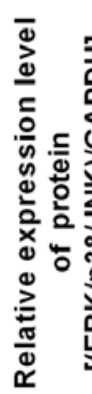
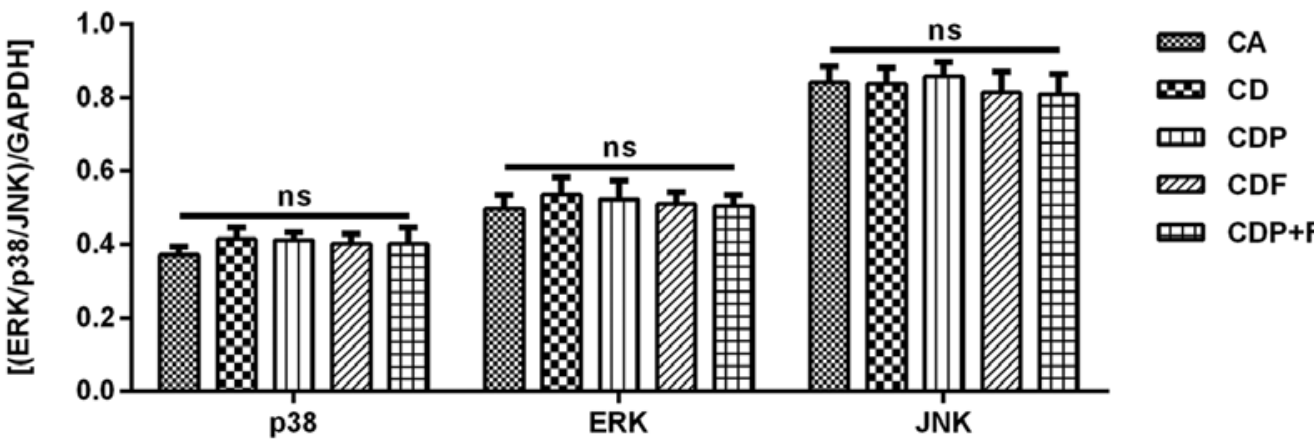

Figure 5. Paroxetine combined with fluorouracil reduces IL-22 levels in mice and can function through the MAPK signaling pathway. ELISAs and western blotting were used to detect the expression of IL-22 in the blood and tumor tissues of mice. MAPK signaling pathway-related proteins were detected using western blotting. (A) Expression of IL-22 in the blood detected by ELISA. (B) Expression of IL-22 and MAPK signaling pathway-related proteins in the tumor tissues detected using western blotting. (C) IL-22 protein expression in the tumor tissues. (D) MAPK signaling pathway-related proteins expression in the tumor tissues. " $\mathrm{P}<0.05$. CA, cancer model group; $\mathrm{CD}$, cancer depression model group; CDP, cancer depression with paroxetine group; CDF, cancer depression with fluorouracil group; $\mathrm{CDP}+\mathrm{F}$, cancer depression with paroxetine and fluorouracil group; IL, interleukin; MAPK, mitogen-activated protein kinase; p, phosphorylated; ns, not significant.

Significantly increased levels of p-p38, p-ERK and p-JNK were found in the $\mathrm{CD}$ group compared to the CA group $(\mathrm{P}<0.05)$ and $\mathrm{p} 38$, ERK and JNK were not significantly changed, indicating that the MAPK signaling pathway was activated. Compared with the $\mathrm{CD}, \mathrm{CDP}$ and $\mathrm{CDF}$ group, in $\mathrm{CDP}+\mathrm{F}$ group the expression of $\mathrm{p}-\mathrm{p} 38, \mathrm{p}-\mathrm{ERK}$ and p-JNK was significantly reduced, while the expression of unphosphorylated p38, ERK and JNK was not significantly different between groups; furthermore, the $\mathrm{CDP}+\mathrm{F}$ group was demonstrated to induce the most pronounced reduction of $\mathrm{p}-\mathrm{p} 38$, $\mathrm{p}$-ERK and $\mathrm{p}-\mathrm{JNK}$ expression $(\mathrm{P}<0.05)$, indicating that MAPK signaling pathway was significantly inhibited (Fig. 5B and D).

\section{Discussion}

The incidence of psychological depression is increasing annually. Globally, $>300$ million people suffer from depression, which is listed by the World Health Organization (WHO) as the single largest factor contributing to global disability (25). Depressive disorder has adverse effects on the occurrence, development and prognosis of malignant tumors (26).In patients with malignant tumors, depression affects immune function, thus altering the occurrence, development and outcomes of malignant tumors $(12,27,28)$. CRC has become one of the most common malignant tumors of the digestive system (29). Of all clinically hospitalized patients with CRC, 28.13-31.04\% of 
patients with breast cancer experience symptoms of depression during the perioperative period, which a significantly higher incidence than in the general population (30-32). In the present study, tumors grew faster in transplanted tumor mice with depressive disorder, with a higher tumor volume than in transplanted tumor mice without chronic mild stress. The dynamic curves of tumor growth demonstrated that CRC tumor volume was associated with depression following prolonged chronic mild stress. Fluorouracil treatment effectively inhibited CRC growth and reduced Ki-67 expression, causing inhibited tumor cell proliferation and promoted tumor cell apoptosis. The combination of antidepressants and chemotherapy drugs may improve depressive behaviors and serve a role in tumor inhibition in tumor-bearing mice with depression. All anti-tumor effects were more obvious with combined treatments. These results demonstrated that depressive disorder may promote tumor development in grafted tumor mice and that combined therapy with antidepressants and chemotherapy drugs may have synergistic roles in improving the depressive behavior of mice, while also inhibiting tumor progression.

Previous research has reported that mental and social dysfunction, including depression, changes cytokine levels in vivo, leading to decreased immune function, which may weaken the inhibitory effects of the immune system on malignant tumor growth (33). In a state of depression, the hypothalamus-pituitary-adrenal axis is activated and the secretion of cortisol hormones by the adrenal gland is increased (34). Cortisol hormones inhibit IL-2, IL-6, TNF and other cytokines, as well as antibodies used by the immune system (35). Antidepressant therapy improves depressive symptoms in patients with malignant tumors and has positive effects on their immune function $(36,37)$. IL-22 is produced following IL-9 stimulation of BW5147 lymphoma cells in mice (38). IL-22 has functions similar to IL-10, inhibiting immunity and inflammation, and exhibits $22 \%$ amino acid homology with IL-10 (39). IL-22 is mainly produced by immune cells such as TH1, TH17 and TH22 cells (40). Numerous chronic diseases, including enteritis, mesenchymal lung disease and rheumatoid arthritis, exhibit increased IL-22 expression (41-43). Previous studies have confirmed that IL-22 can raise acute phase reaction products in hepatocytes (20) and activate pancreatic-related proteins in pancreatic acinar cells (44), indicating that IL-22 serves important roles in the inflammatory response phase. Similarly, IL-22 induces the activation of STAT in various cell lines, including mesangial cells (45), colon epithelial cells (46), nonmelanoma skin cancer (47) and hepatoma cells (20).

A previous study revealed higher IL-22 levels in tumor tissues than in adjacent tissues in patients with hepatocellular carcinoma, with raised IL-22 levels at more developed tumor stages (48). However, the changes and effects of IL-22 expression in patients with tumors and depression are unclear. Significantly increased IL-22 was found in CD group mice, suggesting that IL-22 is associated with the pathogenesis of tumor depression. Antidepressant-selective serotonin reuptake inhibitors have been demonstrated to reduce depressive symptoms and regulate cytokine expression. Paroxetine has been used as the antidepressant treatment for tumor-depressive mice (49). Paroxetine may serve a therapeutic role by reducing the levels of IL-22 in these mice, with a more significant reduction seen by combination with fluorouracil therapy.
This indicates that paroxetine may improve immune status by reducing IL-22 levels and enhancing the therapeutic effect of chemotherapy drugs.

By combining with specific cell surface receptors, cytokines have biological functions in activating cell signal transduction pathways. MAPK is a serine threonine protein kinase in eukaryotic cells and has signal transduction functions in multiple pathways, mediating extracellular signaling into cells $(50,51)$, regulating cell growth, differentiation and migration (52). MAPK is one of the major signal transduction pathways. MAPK family members ERK, p38 and JNK promote cell proliferation and suppress apoptosis to promote tumor development $(53,54)$. Studies have demonstrated that ERK1/2 inhibiters can block the proliferation of colon cancer cells by inducing cell cycle arrest in the S-phase $(55,56)$. IL-22 has been shown to induce ERK1/2 and JNK protein phosphorylation, activate the MEK-ERK/JNK pathway, stimulate the growth of tumor cells and promote tumor cell proliferation while inhibiting tumor cell apoptosis, thus promoting CRC development $(57,58)$. In the present study, it was found that paroxetine alone, fluorouracil alone and paroxetine combined with fluorouracil reduced $\mathrm{p}$-p38, $\mathrm{p}$-ERK and $\mathrm{p}$-JNK protein expression levels. Combining the two drugs has the largest regulatory effect on the MAPK signaling pathway in tumor depression mice.

The aforementioned results indicated that the combination of paroxetine and fluorouracil may inhibit tumor cell growth in mice with CRC and depression by inhibiting the expression of IL-22. Combined treatment regulated the activation of the MAPK signaling pathway, which provided novel ideas for the treatment of patients with CRC and depression.

\section{Acknowledgements}

Not applicable.

\section{Funding}

The current study was supported by the Natural Science Foundation of China (grant no. 81472853).

\section{Availability of data and materials}

The datasets used and/or analyzed during the current study are available from the corresponding author on reasonable request.

\section{Authors' contributions}

HZ designed the research. MC and YL performed the mice experiments. $\mathrm{XD}$ and $\mathrm{CZ}$ conducted histological examinations and western blotting. $\mathrm{HJ}$ and $\mathrm{XC}$ performed cell culture experiments and ELISA. HZ and CZ analyzed the results and wrote the manuscript. All authors read and approved the final manuscript.

\section{Ethics approval and consent to participate}

All animal experiments were approved by the Animal Ethics Committee of the Chinese Medical University (Shenyang, China; approval no. CMU2018178). 


\section{Patient consent for publication}

Not applicable.

\section{Competing interests}

The authors declare that they have no competing interests.

\section{References}

1. Li Q, Liu Y, Su B, Zhao H, Lin Q, Zhu Y, Zhang L, Weng D, Gong $\mathrm{X}$, Sun $\mathrm{X}$ and $\mathrm{Xu} \mathrm{Y}$ : The $\mathrm{CT}$ appearance pattern of radiation-induced lung injury and tumor recurrence after stereotactic body radiation therapy in early stage non-small cell lung cancer. Transl Lung Cancer Res 9: 713-721, 2020.

2. Feng RM, Zong YN, Cao SM and Xu RH: Current cancer situation in China: Good or bad news from the 2018 global cancer statistics? Cancer Commun (Lond) 39: 22, 2019.

3. Kenzik KM, Kent EE, Martin MY, Bhatia S and Pisu M: Chronic condition clusters and functional impairment in older cancer survivors: A population-based study. J Cancer Surviv 10: 1096-1103, 2016.

4. Miller KD, Sauer AG, Ortiz AP, Fedewa SA, Pinheiro PS, Tortolero-Luna G, Martinez-Tyson D, Jemal A and Siegel RL: Cancer statistics for hispanics/latinos, 2018. CA Cancer J Clin 68: 425-445, 2018

5. Chen W, Zheng R, Baade PD, Zhang S, Zeng H, Bray F, Jemal A, Yu XQ and He J: Cancer statistics in China, 2015. CA Cancer J Clin 66: 115-132, 2016.

6. Zamora-Ros R, Shivappa N, Steck SE, Canzian F, Landi S, Alonso MH, Hébert JR and Moreno V: Dietary inflammatory index and inflammatory gene interactions in relation to colorectal cancer risk in the bellvitge colorectal cancer case-control study. Genes Nutr 10: 447, 2015.

7. Raskov H, Pommergaard HC, Burcharth J and Rosenberg J: Colorectal carcinogenesis-update and perspectives. World J Gastroenterol 20: 18151-18164, 2014.

8. Gu MJ, Huang QC, Bao CZ, Li YJ, Li XQ, Ye D, Ye ZH, Chen K and Wang JB: Attributable causes of colorectal cancer in China BMC Cancer 18: 38, 2018.

9. Wang X, Wang B, Zhao J, Liu C, Qu X and Li Y: MiR-155 is involved in major depression disorder and antidepressant treatment via targeting SIRT1. Biosci Rep 38: BSR20181139, 2018.

10. Kosari-Nasab M, Shokouhi G, Ghorbanihaghjo A, Abbasi MM and Salari AA: Hesperidin attenuates depression-related symptoms in mice with mild traumatic brain injury. Life Sci 213 198-205, 2018.

11. Rooney AG, McNamara S, Mackinnon M, Fraser M, Rampling R, Carson A and Grant R: The frequency, longitudinal course, clinical associations, and causes of emotional distress during primary treatment of cerebral glioma. Neuro oncol 15: 635-643, 2013.

12. Hong JS and Tian J: Prevalence of anxiety and depression and their risk factors in Chinese cancer patients. Support Care Cancer 22: 453-459, 2014.

13. Van Gorp H and Lamkanfi M: The emerging roles of inflammasome-dependent cytokines in cancer development. EMBO Rep 20: e47575, 2019.

14. Nocera NF, Lee MC, De La Cruz LM, Rosemblit C and Czerniecki BJ: Restoring lost anti-HER-2 Th1 immunity in breast cancer: A crucial role for Th1 cytokines in therapy and prevention. Front Pharmacol 7: 356, 2016.

15. Sconocchia G, Eppenberger S, Spagnoli GC, Tornillo L, Droeser R, Caratelli S, Ferrelli F, Coppola A, Arriga R, Lauro D, et al: NK cells and T cells cooperate during the clinical course of colorectal cancer. Oncoimmunology 3: e952197, 2014.

16. Kryczek I, Lin Y, Nagarsheth N, Peng D, Zhao L, Zhao E, Vatan L, Szeliga W, Dou Y, Owens S, et al: $\mathrm{IL}_{-22}{ }^{+} \mathrm{CD}^{+} \mathrm{T}$ cells promote colorectal cancer stemness via STAT3 transcription factor activation and induction of the methyltransferase DOT1L. Immunity 40: 772-784, 2014

17. Huang YH, Cao YF, Jiang ZY, Zhang S and Gao F: Th22 cell accumulation is associated with colorectal cancer development. World J Gastroenterol 21: 4216-4224, 2015.

18. Trifari S, Kaplan CD, Tran EH, Crellin NK and Spits H: Identification of a human helper $\mathrm{T}$ cell population that has abundant production of interleukin 22 and is distinct from $\mathrm{TH}-17$, TH 1 and TH 2 cells. Nat Immunol 10: 864-871, 2009.
19. Lejeune D, Dumoutier L, Constantinescu S, Kruijer W, Schuringa JJ and Renauld JC: Interleukin-22 (IL-22) activates the JAK/STAT, ERK, JNK, and p38 MAP kinase pathways in a rat hepatoma cell line pathways that are shared with and distinct from IL-10. J Biol Chem 277: 33676-33682, 2002.

20. Liu Y, Pan W, Yang S, Wu X, Wu J, Ma J, Yuan Z and Meng S: Interleukin-22 protects rat PC12 pheochromocytoma cells from serum deprivation-induced cell death. Mol Cell Biochem 371: 137-146, 2012.

21. Yu H, Fan C, Yang L, Yu S, Song Q, Wang P and Mao X Ginsenoside Rg1 prevents chronic stress-induced depression-like behaviors and neuronal structural plasticity in rats. Cell Physiol Biochem 48: 2470-2482, 2018.

22. Andrus BM, Blizinsky K, Vedell PT, Dennis K, Shukla PK, Schaffer DJ, Radulovic J, Churchill GA and Redei EE: Gene expression patterns in the hippocampus and amygdala of endogenous depression and chronic stress models. Mol Psychiatry 17: 49-61, 2012.

23. Porsolt RD, Le Pichon M and Jalfre M: Depression: A new animal model sensitive to antidepressant treatments. Nature 266 730-732, 1977.

24. Osanloo N, Najafi-Abedi A, Jafari F, Javid F, Pirpiran M, Memar Jafari MR, Khosravi SAM, Behzadi MR, Ranjbaran M and Sahraei H: Papaver rhoeas L. hydroalcoholic extract exacerbates forced swimming test-induced depression in mice. Basic Clin Neurosci 7: 195-202, 2016.

25. Smith K: Mental health: A world of depression. Nature 515: 181, 2014.

26. Mugge L, Mansour TR, Crippen M, Alam Y and Schroeder J: Depression and glioblastoma, complicated concomitant diseases: A systemic review of published literature. Neurosurg Rev 43 497-511, 2020.

27. Dowlati Y, Herrmann N, Swardfager W, Liu H, Sham L, Reim EK and Lanctôt KL: A meta-analysis of cytokines in major depression. Biol Psychiatry 67: 446-457, 2010.

28. Thaker PH, Han LY, Kamat AA, Arevalo JM, Takahashi R, Lu C, Jennings NB, Armaiz-Pena G, Bankson JA, Ravoori M, et al: Chronic stress promotes tumor growth and angiogenesis in a mouse model of ovarian carcinoma. Nat Med 12: 939-944, 2006.

29. Jemal A, Bray F, Center MM, Ferlay J, Ward E and Forman D: Global cancer statistics. CA Cancer J Clin 61: 69-90, 2011.

30. Quach C, Sanoff HK, Williams GR, Lyons JC and Reeve BB: Impact of colorectal cancer diagnosis and treatment on health-related quality of life among older Americans: A population-based, case-control study. Cancer 121: 943-950, 2015.

31. Shaheen Al Ahwal M, Al Zaben F, Khalifa DA, Sehlo MG, Ahmad RG and Koenig HG: Depression in patients with colorectal cancer in Saudi Arabia. Psychooncology 24: 1043-1050, 2015.

32. White AJ, Reeve BB, Chen RC, Stover AM and Irwin DE: Coexistence of urinary incontinence and major depressive disorder with health-related quality of life in older Americans with and without cancer. J Cancer Surviv 8: 497-507, 2014.

33. Santos JC and Pyter LM: Neuroimmunology of behavioral comorbidities associated with cancer and cancer treatments. Front Immunol 9: 1195, 2018.

34. Ehlert U, Gaab J and Heinrichs M: Psychoneuroendocrinological contributions to the etiology of depression, posttraumatic stress disorder, and stress-related bodily disorders: The role of the hypothalamus-pituitary-adrenal axis. Biol Psychol 57: 141-152, 2001.

35. Wang J, Chen Y, Dai C, Shang Y and Xie J: Ginsenoside Rh2 alleviates tumor-associated depression in a mouse model of colorectal carcinoma. Am J Transl Res 8: 2189-2195, 2016.

36. Hawkins NA, Soman A, Buchanan Lunsford N, Leadbetter S and Rodriguez JL: Use of medications for treating anxiety and depression in cancer survivors in the United States. J Clin Oncol 35: 78-85, 2017

37. Kulkarni SK and Dhir A: Current investigational drugs for major depression. Expert Opin Investig Drugs 18: 767-788, 2009.

38. Dumoutier L, Louahed J and Renauld JC: Cloning and characterization of IL-10-related T cell-derived inducible factor (IL-TIF), a novel cytokine structurally related to IL-10 and inducible by IL-9. J Immunol 164: 1814-1819, 2000.

39. Logsdon NJ, Jones BC, Josephson K, Cook J and Walter MR: Comparison of interleukin-22 and interleukin-10 soluble receptor complexes. J Interferon Cytokine Res 22: 1099-1112, 2002.

40. Rutz S, Eidenschenk C and Ouyang W: IL-22, not simply a Th17 cytokine. Immunol Rev 252: 116-132, 2013. 
41. Brand S, Beigel F, Olszak T, Zitzmann K, Eichhorst ST, Otte JM, Diepolder H, Marquardt A, Jagla W, Popp A, et al: IL-22 is increased in active Crohn's disease and promotes proinflammatory gene expression and intestinal epithelial cell migration. Am J Physiol Gastrointest Liver Physiol 290: G827-G838, 2006.

42. Ikeuchi H, Kuroiwa T, Hiramatsu N, Kaneko Y, Hiromura K, Ueki K and Nojima Y: Expression of interleukin-22 in rheumatoid arthritis: Potential role as a proinflammatory cytokine. Arthritis Rheum 52: 1037-1046, 2005.

43. Wolk K, Kunz S, Witte E, Friedrich M, Asadullah K and Sabat R: IL-22 increases the innate immunity of tissues. Immunity 21 : 241-254, 2004

44. Gurney AL: IL-22, a Th1 cytokine that targets the pancreas and select other peripheral tissues. Int Immu nopharmacol 4: 669-677, 2004.

45. Aujla SJ and Kolls JK: IL-22: A critical mediator in mucosal host defense. J Mol Med (Berl) 87: 451-454, 2009.

46. Nagalakshmi ML, Rascle A, Zurawski S, Menon S and de Waal Malefyt R: Interleukin-22 activates STAT3 and induces IL-10 by colon epithelial cells. Int Immunopharmacol 4: 679-691, 2004.

47. Nardinocchi L, Sonego G, Passarelli F, Avitabile S, Scarponi C, Failla CM, Simoni S, Albanesi C and Cavani A: Interleukin-17 and interleukin-22 promote tumor progression in human nonmelanoma skin cancer. Eur J Immunol 45: 922-931, 2015.

48. Park O, Wang H, Weng H, Feigenbaum L, Li H, Yin S, Ki SH, Yoo SH, Dooley S, Wang FS, et al: In vivo consequences of liver-specific interleukin-22 expression in mice: Implications for human liver disease progression. Hepatology 54: 252-261, 2011.

49. Herzallah MM, Moustafa AA, Natsheh JY, Danoun OA Simon JR, Tayem TI, Sehwail MA, Amleh I, Bannoura I, Petrides G, et al: Depression impairs learning, whereas the selective serotonin reuptake inhibitor, paroxetine, impairs generalization in patients with major depressive disorder. J Affect Disord 151: 484-492, 2013.
50. Chang L and Karin M: Mammalian MAP kinase signalling cascades. Nature 410: 37-40, 2001.

51. Devendrakumar KT, Li X and Zhang Y: MAP kinase signalling: Interplays between plant PAMP-and effector-triggered immunity. Cell Mol Life Sci 75: 2981-2989, 2018.

52. Zhang X, Liu W, Li Y, Li G and Xu JR: Expression of HopAI interferes with MAP kinase signalling in magnaporthe oryzae. Environ Microbiol 19: 4190-4204, 2017

53. Guo C, Hou J, Ao S, Deng X and Lyu G: HOXC10 up-regulation promotes gastric cancer cell proliferation and metastasis through MAPK pathway. Chin J Cancer Res 29: 572-580, 2017.

54. Zhang G, Cheng Y, Zhang Q, Li X, Zhou J, Wang J and Wei L: ATX-LPA axis facilitates estrogen-induced endometrial cancer cell proliferation via MAPK/ERK signaling pathway. Mol Med Rep 17: 4245-4252, 2018.

55. Park SS, Park SK, Lim JH, Choi YH, Kim WJ and Moon SK: Esculetin inhibits cell proliferation through the Ras/ERK1/2 pathway in human colon cancer cells. Oncol Rep 25: 223-230, 2011.

56. Meloche S and Pouysségur J: The ERK1/2 mitogen-activated protein kinase pathway as a master regulator of the G1-to S-phase transition. Oncogene 26: 3227-3239, 2007.

57. Kim K, Kim G, Kim JY, Yun HJ, Lim SC and Choi HS: Interleukin-22 promotes epithelial cell transformation and breast tumorigenesis via MAP3K8 activation. Carcinogenesis 35: 1352-1361, 2014.

58. Tan AHM and Lam KP: Pharmacologic inhibition of MEK-ERK signaling enhances Th17 differentiation. J Immunol 184: $1849-1857,2010$.

This work is licensed under a Creative Commons Attribution-NonCommercial-NoDerivatives 4.0 International (CC BY-NC-ND 4.0) License. 